\title{
AS TRAmas DA AmBIGUIDADE EXPERIÊnCIA IDEnTITÁRIA TRAVESTI E ESTRATÉGIAS DE SUBVERSÃO
}

\author{
Tuanny Soeiro Sousa ${ }^{44}$
}

É. Mas parece que chegou o instante de aceitar em cheio a misteriosa vida dos que um dia vão morrer. Tenho que começar por aceitar-me e não sentir o horror punitivo de cada vez que eu caio, pois quando eu caio a raça humana em mim também cai. Aceitar-me plenamente? É uma violentação de minha vida. Cada mudança, cada projeto novo causa espanto: meu coração está espantado. É por isso que toda a minha palavra tem um coração onde circula sangue.

Clarice Lispector, Um sonho de vida.

\section{RESUMO}

O presente trabalho tem a intenção de analisar a desnaturalização dos conceitos de sexo, gênero e sexualidade, objetivando examinar se essas categorias constroem processos de normalização e fabricação do sujeito humano. Parte-se da hipótese de que a experiência identitária travesti consegue demonstrar o caráter construído de todas as identidades. Para o desenvolvimento do trabalho, optou-se por revisar algumas teorias sobre a construção discursiva do gênero e da sexualidade, além de utilizar dados colhidos em pesquisas etnográficas sobre travestis.

Palavras-chave: Travesti. Gênero. Subversão.

\section{INTRODUÇÃO}

O presente artigo objetiva analisar o quão tênue são as identidades sexuais e de gênero que, por mais que pareçam estáveis, são, o tempo todo, abaladas por experiências identitárias que não correspondem às expectativas de inteligibilidade do sexo e do gênero, como as travestis.

44 Mestranda em Direito e Instituições do Sistema de Justiça pela Universidade Federal do Maranhão. Graduanda em Ciências Sociais pela Universidade Federal do Maranhão. Graduada em Direito pela Unidade de Ensino Superior Dom Bosco. São Luís, Maranhão, Brasil. 
A hipótese do trabalho reside na afirmação de que a identidade travesti, através de atos estilizados que transformam o considerado "corpo macho" em uma identidade feminina, consegue desvendar o caráter performativo e, portanto, construído de todas as identidades de gênero, não existindo, assim, naturalização dessa categoria.

Os conceitos aqui empregados são resultados de uma ampla revisão bibliográfica acerca da construção discursiva das categorias gênero, sexo e sexualidade. Outrossim, os relatos acerca das experiências vividas por travestis são provenientes de estudos etnográficos realizados no Brasil acerca desse seguimento.

Para saber como surgem e atuam as normas de gênero, o primeiro tópico se deterá no processo de desnaturalização do corpo, do gênero e da sexualidade, demonstrando como essas categorias constroem em conjunto, dispositivos que aprisionam, no corpo, a verdade acerca dos indivíduos.

Em seguida, são trazidos alguns estudos sobre experiência trans, para tentar compreender quem são as travestis e como elas constroem as suas subjetividades femininas, ainda que tenham nascido com um corpo intitulado como masculino.

Por último, intenta-se analisar o conceito de gênero performativo, com o objetivo de desvendar que tecnologias fabricam corpos-machos e corpos-fêmeas, e como os discursos são interpretados para dar vida aos gêneros.

\section{A (RE)INVENÇÃO DO CORPO E A (DES)CONSTRUÇÃO DAS BARREIRAS DISCURSIVAS DO SEXO}

Tem-se por finalidade a contextualização das noções de sexo, gênero e sexualidade; conceitos esses que engendram a inteligibilidade da identidade contemporânea dos sujeitos. Pretende-se expor que essas noções não possuem uma natureza ontológica e imutável, mas sim que são consequências do momento histórico e cultural a que os indivíduos estão sujeitos. 
Como forma de tentar explicar como determinados discursos são construídos, Butler (2003) explica que os sistemas jurídicos produzem os sujeitos que deseja representar. Os sujeitos são regulados de forma negativa pelos sistemas jurídicos. Contudo, ao mesmo tempo em que regula esses sujeitos, a vida política depende dos mesmos, surgindo a necessidade de produzir esses personagens conforme as suas próprias exigências. Desse modo, o sujeito regulado é, antes de representado, produzido pelo próprio sistema que o representa.

O processo de criação não é claro. Ele é ocultado para que os sujeitos notem apenas as suas representações.

No processo de criação da matriz heterossexual, alguns indivíduos parecem romper com os papéis binários de masculino e feminino, tais quais as travestis; e como sanção, são taxadas de anormais, desviantes, estando quase sempre em uma situação de marginalização frente a outras identidades.

Entretanto, a própria norma que as exclui também as produz, pois são nas brechas do discurso que as travestis irão constituir as suas subjetividades. É nesse sentido que apregoa Zambrano:

\begin{abstract}
As "fugas momentâneas" são imprescindíveis, e são respaldadas pelo sistema como estratégia que o afirma e o solidifica. Até a próxima fissura, dúvida escape. Assim como o "carnaval" passa a ser indispensável para reiterar a norma e a ordem, sem este, talvez, fosse impossível se sujeitar a um sistema tão inflexível como do sistema binário heteropatriarcal ${ }^{45}$ (ZAMBRANO, 2006, p. 16).
\end{abstract}

Partindo das ideias de Butler (2003) de que se deve romper com o conceito de uma verdade pré-discursiva sobre o sexo, o presente tópico se deterá no desvendamento dos discursos que enredam as tramas dos sujeitos ocidentais, demonstrando que as identidades não estão limitadas a categorização.

No senso comum, o sexo parece estar diretamente ligado à classificação dos seres humanos no que tange à sua capacidade de reprodução. De acordo com o dicionário Aurélio, sexo, do latim sexu, é conceituado como a "conformação

45 Tradução nossa. 
particular que distingue o macho da fêmea, nos animais e nos vegetais, atribuindoIhes um papel determinado na geração e conferindo-Ihes certas características distintivas" (AURÉLIO, 2004, p. 1589).

A partir do conceito do dicionário, é possível se depreender que ter um sexo é, de acordo com o papel reprodutivo acoplado a algumas características, ser macho ou fêmea. Já ser fêmea, nos termos do Aurélio (2004, p. 768) é possuir um sexo feminino; ser mulher. À primeira vista, o dicionário permeia uma questão óbvia no que tange à existência do ser humano: para dar luz a si, deve, antes de tudo, ser macho ou fêmea, cada qual dotado de características específicas que contrastam ao mesmo tempo em que se completam. Logo, ser fêmea é não ser macho, na medida em que sua genitália naturalmente determina, para em seguida ser mulher, ser do lar, ser casada, ser mãe; enquanto o macho é homem, é trabalhador, é casado, é pai. Dentro do pensamento comum, o sexo não é só um determinante biológico, mas, sobretudo, um determinante social.

Entretanto, será que a partir do ponto de vista das ciências biológicas, podem os seres humanos efetivamente serem divididos em duas categorias distintas?

Segundo Hilaire (2000, p. 95), existem algumas variáveis que concorrem para a definição do sexo: o sexo genético ou cromossômico, o sexo hormonal, o sexo hipotalâmico, o sexo designado, o sexo de referência na educação, o gênero e os papéis sexuais e o sexo procriador.

De acordo com uma teoria que perdurou durante muitos anos, o sexo do embrião poder ser observado após seis ou sete semanas de gestação, e surge sob o efeito dos hormônios pré-natais. Já outros estudos apontam que a diferenciação poderia ocorrer antes mesmo da entrada em ação dos hormônios, o que denota que o debate sobre quais signos permitiriam o desenvolvimento de ovários e testículos ainda está em aberto. Contudo, o que concerne apontar, é que foi demonstrado que a presença do cromossomo $Y$ pode ser observada em pessoas dotadas de órgãos sexuais femininos, bem como muitos casos de anomalia genética foram observados, acompanhados ou não de anomalia de 
órgãos (HILAIRE, 2000, p. 95 e 96). Machos ou fêmeas? Mulheres ou homens? Se o sexo está diretamente ligado ao corpo, e as próprias ciências biológicas não conseguem definir o papel destes sujeitos, como classificá-los? Quem os decide?

De acordo com Butler (2010, p. 153 e 154), a diferença sexual não é nunca uma função de diferenças materiais, que não sejam, ao mesmo tempo, marcadas e formadas por práticas discursivas. Nesse sentido, o sexo não pode ser concebido como um aparato neutro e natural, primeiramente porque "o próprio conceito de natural deve ser repensado, pois o conceito de natureza tem uma história" (BUTLER, 2010, p. 157), depois porque "não há como recorrer a um corpo que já não tenha sido interpretado por meio de significados culturais; consequentemente, o sexo não poderia qualificar-se como facticidade anatômica pré-discursiva" (BUTLER, 2003, p. 2007).

Para a autora, sexo se trata, na verdade, de um ideal regulatório, em que funciona não apenas como uma norma, mas é parte de uma prática regulatória que visa controlar os corpos que governa, isto é, "toda força regulatória manifestase como uma espécie de poder produtivo, o poder de produzir - demarcar, fazer, circular, diferenciar - os corpos que ele controla" (BUTLER, 2010, p. 153 e 154).

Essa materialização não ocorre de forma simples, ou seja, ela não é estabelecida de uma hora para outra, o sexo é forçosamente normatizado como material através do tempo, o que significa dizer que essa materialização é imposta através da reiteração da norma regulatória; norma essa que necessita de reiteração porque a materialização nunca é totalmente completa, e os corpos não se conformam nunca às normas pelas quais sua materialização é imposta (BUTLER, 2010, p. 154).

É importante que se tenha em mente que a performatividade do gênero se relaciona com essa concepção de materialidade, na medida em que as normas regulatórias do sexo trabalham para construir a materialização do corpo/sexo/diferença sexual, a serviço da consolidação do imperativo heterossexual (BUTLER, 2010, p. 154). 
Para que se entenda melhor, é necessário se proclame a citação da célebre frase de Beauvoir: "não se nasce mulher, torna-se mulher" (BEAUVOIR, 1980, p. 9). Para a filósofa, ser o sujeito mulher não é um dado natural, em que se nasce fêmea e consecutivamente mulher, é sim, uma propriedade cultural, que nas palavras de Butler (2010) significa "a prática reiterativa e citacional pela qual o discurso produz os efeitos que ele nomeia" (Butler, 2010, p. 154). A norma determina que o gênero seja inscrito sobre uma estrutura neutra, o sexo, determinando, portando, um ponto de aprisionamento quanto a identidade social deste sujeito cuja inteligibilidade tem a intenção de manter o desejo heterossexual como a sexualidade dominante.

Em conformidade com os ensinamentos de Butler, Louro (2010) explica que assim como o sexo, a sexualidade também é compreendida como um atributo natural. Tal ponto de vista, de acordo com a autora, parte da ideia de que as identidades de gênero são sempre decorrentes das identidades sexuais, como se o corpo fosse a base sólida da identificação dos seres. Não obstante, a sexualidade também aparece como um dado natural derivado desta identidade de gênero/sexual, onde a continuidade lógica, ou seja, a sua inteligibilidade, se faz obrigatória.

Tal concepção usualmente se ancora no corpo e na suposição de que todos vivemos nossos corpos, universalmente, da mesma forma. No entanto, podemos entender que a sexualidade envolve rituais, linguagens, fantasias, representações, símbolos, convenções... Processos profundamente culturais e plurais (LOURO, 2010, p. 11).

A partir dessa perspectiva, a autora também conclui que não existe nada de natural nesse processo todo, a começar pela própria concepção de corpo, ou mesmo de natureza. Para Louro (2010), é através de processos culturais que definimos o que é e o que não é natural; "produzimos e transformamos a natureza e a biologia e, consequentemente, as tornamos históricas" (LOURO, 2010, p. 11).

Hilaire (2000) aponta que os estudos de Foucault se destinaram a analisar como, historicamente, a verdade sobre o sexo foi produzida pelas disciplinas científicas e como as instituições médicas e pedagógicas as 
substituíram por meio de procedimentos destinados a normalizar a verdade sobre o sexo.

Foucault (2009) entende a sexualidade como um dispositivo histórico. Em outras palavras, ela é constituída historicamente através de discursos. Para se entender com mais clareza o conceito de dispositivo, o autor explica que se trata de:

Um conjunto decididamente heterogêneo que engloba discursos, instituições, organizações arquitetônicas, decisões regulamentares, leis, medidas administrativas, enunciados científicos, proposições filosóficas, morais, filantrópicas. Em suma, o dito e o não dito são os elementos do dispositivo. O dispositivo é a rede que se pode estabelecer entre estes elementos (FOUCAULT, 2010, p. 244).

É neste contexto que os corpos ganham sentido socialmente. As identidades de gênero e sexuais são inscritas a partir de uma determinada cultura, bem como a sexualidade é socialmente estabelecida. "As identidades de gênero e sexuais são, portanto, compostas e definidas por relações sociais, elas são moldadas pelas redes de poder de uma sociedade" (LOURO, 2010, p. 11).

Nos ensinamentos de Louro (2010, p. 12), não só as identidades de gênero e sexuais são inscritas no âmbito da cultura e da história, mas todas as identidades sociais, sendo que essas múltiplas identidades constituem os sujeitos a partir do momento em que são interpelados a se reconhecerem em uma identidade, ao mesmo tempo em que se estabelecem em um dado grupo social. A autora ainda afirma que não existe simplicidade nesse processo, uma vez que tais identidades podem cobrar valores distintos e contraditórios.

\begin{abstract}
Essas múltiplas identidades sociais podem ser, também, provisoriamente atraentes e, depois, nos parecerem descartáveis; elas podem ser, então, rejeitadas e abandonadas. Somos sujeitos de identidades transitórias e contingentes. Portanto, as identidades sexuais e de gênero (como todas as identidades sociais) têm caráter fragmentário, instável, histórico e plural, afirmado pelos teóricos e teóricas culturais (LOURO, 2010, p. 12).
\end{abstract}

Parece admissível que determinadas identidades sejam, de fato, contingentes. As identidades de classe, por exemplo, em tempos em que os discursos vendem a ideia de necessidade de ascensão social, parecem viabilizar a 
aceitação da imagem de um operário virando patrão. Em contrapartida, a identidade de gênero é naturalizada a ponto de se isolar atrás de uma barreira intransponível, impossibilitando que outras manifestações de identidade sejam viáveis.

Louro (2010, p. 13) elucida que tal inflexibilidade decorre do medo da incerteza e do desconhecido que implica não ter uma identidade fixa. Como em geral reconhece-se que as pessoas possam ter identidades múltiplas, é através da demarcação do corpo que os indivíduos irão se determinar, porque o corpo parece uma inequívoca evidência por si, e aparentemente se deduz que as identidades sexuais e de gênero transcorrem das marcas biológicas.

Contudo, é indispensável para o real entendimento do estudo, que sejam questionadas como determinadas características passaram a ser reconhecidas como marcas definidoras da identidade, e quais os significados que estão sendo atribuídos, nesse momento, a estas marcas.

\begin{abstract}
O corpo é inconstante [...]. O corpo se altera com a passagem do tempo, com a doença, com mudanças de hábitos alimentares e de vida, com possibilidades distintas de prazer ou com novas formas de intervenção médica e tecnológica. Num tempo de AIDS, por exemplo, a preocupação com o exercício do "sexo seguro" vem sugerindo novos modos de encontrar prazer corporal, alterando práticas sexuais ou produzindo outras formas de relacionamento entre os sujeitos (LOURO, 2010, p. $14 \mathrm{e}$ $15)$.
\end{abstract}

Com essa passagem, a autora aparece sugerindo que os corpos, ao contrário que se pensa, não são imutáveis a ponto de que se ancore a identidade, pelo contrário, estão, a todo o momento, passando por transformações. O corpo, assim como o sexo, é moldado pelas relações sociais.

É possível se compreender, então, como a norma corporal é assumida, apropriada, adotada e como ela não é algo que se passa com um sujeito, mas que o sujeito "é formado em virtude de ter passado por esse processo de assumir um sexo" (BUTLER, 2010, p. 155).

Butler (2010) ensina como a formação dos sujeitos exige uma identificação com o fantasma normativo do sexo: 
Essa identificação ocorre através de um repúdio que produz um domínio de abjeção, um repúdio sem o qual o sujeito não pode emergir. Trata-se de um repúdio que cria a valência da "abjeção" - e seu status para o sujeito - como um espectro ameaçador. Além disso, a materialização de um sexo diz respeito, centralmente, à regulação de práticas identificatórias de forma que a abjeção negada ameaçará denunciar as presunções autofundantes do sujeito sexuado, fundado como está aquele sujeito num repúdio cujas consequências não pode controlar (BUTLER, 2010, p. 156).

Logo, para que o indivíduo adquira o status de sujeito, antes de qualquer coisa, a norma exige a identificação sexuada do mesmo. A partir do momento em que se transforma em sujeito, o indivíduo cria uma zona de exclusão, ou melhor, de separação entre o sujeito e o não sujeito, espaço esse denominado de zona de abjeção. O abjeto é designado como as zonas "inóspitas" e inabitáveis da vida social, que são povoadas por aqueles que não gozam do status de sujeito (BUTLER, 2010, p. 155).

Em outro ensaio, Butler (2003) assevera ainda, que a constituição do status de pessoa não está somente ligada à identificação sexual do indivíduo, mas principalmente ao adquirir seu gênero em conformidade com padrões reconhecíveis de inteligibilidade do gênero.

Gêneros "inteligíveis" são aqueles que, em certo sentido, instruem e mantêm relações de coerência e continuidade entre sexo, gênero, prática sexual e desejo. Em outras palavras, os espectros de descontinuidade e incoerência, eles próprios só são concebíveis em relação a normas existentes de continuidade e coerência, são constantemente proibidos e produzidos pelas próprias leis que buscam estabelecer linhas causais ou expressivas de ligação entre o sexo biológico, o gênero culturalmente constituído e a "expressão" ou "efeito" de ambos na manifestação do desejo sexual por meio de prática sexual (BUTLER, 2003, p. 38).

Depreende-se, portanto, que a matriz heteronormativa exige a instituição de posições discriminadas e assimétricas entre feminino e masculino, em que estes são compreendidos como atributos expressivos de macho e fêmea. Essa mesma matriz requer ainda, que certas identidades não possam existir, isto é, aquelas em que o gênero não decorre do sexo e aquelas em que as práticas do desejo não decorrem nem do sexo, nem do gênero. 'Nesse contexto, 'decorrer' seria uma relação política de direito instituída pelas leis culturais que estabelecem 
e regulam a forma e o significado da sexualidade" (BUTLER, 2003, p. 39). Consequentemente, tanto o sexo, quanto o gênero e a sexualidade, não são aquilo que alguém tem ou a descrição estática daquilo que alguém é, mas sim, a norma regulatória pelas quais o alguém se torna viável.

\section{E QUE O MESMO SIGNO QUE EU TENTO LER E SER É APENAS UM POSSÍVEL E O IMPOSSÍVEL EM MIM ${ }^{46}$}

Quando se parte de noções que determinam os sujeitos em posições cristalizadas, fica difícil figurar a identidade de um ser que se exibe de forma tão ambígua. Pensar as travestis, diante do sexo fixo, parece subverter a ordem das coisas. Se a identidade pressupõe prosseguimento da ordem lógica do biológico, do papel cultural e da manifestação do desejo, como encaixar esses sujeitos que parecem inverter a ótica daquilo que é dado como certo? Onde se determinam as travestis no universo binário heteronormativo? Homens de peito? Mulheres de pau? Qual o gênero da travesti?

Em pesquisa etnográfica realizada durante oito meses com as travestis de Salvador, Kulick (2008), ao questionar o porquê de alguns indivíduos se engajarem em práticas de mudança corporais - como as fazem as travestis ingerindo ou se aplicando hormônios, bem como colocado silicone industrial -, esperava ouvir que as travestis desejavam um corpo feminino por se sentirem mulher, contudo, não foi essa a resposta que Ihe foi dada. Conforme narra: "a mim, nenhuma delas jamais disse que era uma mulher presa no corpo de um homem" (KULICK, 2008, p.100).

A observação de Kulick serve para evidenciar que a travesti não deseja ser uma mulher. Ao responder a pergunta do antropólogo, todas as travestis se limitaram a dizer que passavam por processo de mudança corporal para se sentirem mais femininas, entretanto, o autor assevera que a semelhança que faziam de si mesmas frente às mulheres se limitou a atributos externos, tal qual a

46 Fragmentos da música Sou Neguinha. Composição e interpretação: Caetano Veloso. 
aparência física, mas nunca a essência interna. A subjetividade da travesti, aqui, aparece em contraste com a subjetividade da mulher.

Em contraposição, ainda que desejem uma aparência eminentemente feminina, o mesmo autor vai apontar que não almejam se desfazer da genitália masculina, ou seja, ao mesmo tempo que corporificam algo em torno de uma feminilidade, mantêm intacto o maior símbolo de masculinidade presente em uma sociedade patriarcal como a que se vive no mundo contemporâneo ocidental.

Ainda no mesmo ensaio, Kulick evidencia que no Brasil, atividade e passividade têm sido, respectivamente, ainda que em um universo homoafetivo exclusivamente masculino, relacionadas à masculinidade e feminilidade; e inclusive neste aspecto a travesti aparece ambígua, pois ficou claro que, não só na pesquisa de Kulick, como também nas pesquisas de Silva (2007) e Benedetti (2005), que estas tendem a assumir tanto um papel ativo, quanto um papel passivo durante as relações sexuais.

Apreende-se, portanto, que os sujeitos aqui estudados parecem flutuar perante os papéis normatizados, sem, contudo, se localizarem em algum deles; 0 que culminará no seu status de sub-humanidade.

Ao traçar o perfil histórico do universo homoerótico brasileiro, Garcia (2007) ensina que o até meados década de 70 era predominante a estrutura dos papéis sexuais na díade ativo/passivo, em que a relação sexual pressupunha a existência de um passivo e de um ativo, sendo as figuras remetidas à feminilidade e masculinidade, respectivamente.

$\mathrm{Na}$ década de 20 surge a figura do "fresco", que externaliza um comportamento que é comparado ao das mulheres, mostrando preferência pelo comportamento sexual passivo. Os jornais da época relacionam a figura do "fresco" à prostituição, entretanto, como a prostituição de homens quase não era praticada, sugere-se que essa associação era muito mais imaginária que real (GARCIA, p. 32).

$\mathrm{Na}$ década de 20 nasce o "veado", e na década de 30 o termo "bicha", ambos relacionados a indivíduos sexualmente passivos. Na década de 50 começa 
a aparecer o "entendido", ou seja, o indivíduo que parece se movimentar perante essa díade. Na década de 70 surge a identidade gay. (GARCIA, p. 45).

O termo travesti, conforme ensina Garcia, até os anos 60 , se reservava aos indivíduos que se vestiam de mulher, em paródias carnavalescas, em shows, ou mesmo no cotidiano. Silva (2007, p. 181) acrescenta que se tratava de um universo de confinamento, em que a identidade parece restrita ao voyeurismo, fetichismo, teatro, carnaval ou praia deserta.

É só a partir da década de 70 que a travesti vai aparecer como figura que se prostitui nos centros das cidades. Aqui, já é possível se evidenciar a busca do macho pelo corpo feminino, configurado não só através dos adereços próprios das mulheres, tais quais as vestimentas, esmalte, maquiagem, etc, como também a procura pela transformação corporal através dos hormônios e do uso de silicone.

Garcia (2007, p. 48) associa o surgimento das travestis contemporâneas às novas maneiras de transformação corpórea, que possibilitaram uma maior aproximação à aparência do corpo feminino. Um segundo motivo pode ser apontado como a desigualdade de classes crescente durante a década de 70, o que culminou na necessidade de prostituição de determinados gays, em especial os femininos, socialmente mais excluídos, que não conseguiam se inserir no mercado de trabalho em decorrência de suas estigmatizações.

Autores como Silva (2007), Benedette (2005) e Kulick (2008) defendem a ideia de que as travestis começam a construir sua subjetividade a partir do momento em que iniciam suas transformações corporais. Em geral, como ensina Kulick, ainda menino, a futura travesti irá se deparar com o desejo homossexual, sendo, em seguida, rejeitada pela família. Quando começam os primeiros contatos com outras travestis, começam a dar vida à sua própria essência, ou seja, à sua transformação através dos hormônios ingeridos e da colocação de silicone industrial pelas "bombadeiras".

Essa transformação que dá vida não só ao novo corpo, como também à nova identidade, fica bem clara na fala da personagem Agrado, no filme "Tudo sobre minha mãe" de Pedro Almodóvar, conforme pode ser observada: 
Me chamo Agrado, porque toda minha vida sempre tento agradar aos outros. Além de agradável, sou muito autêntica. Vejam que corpo. Feito à perfeição. Olhos amendoados: 80 mil. Nariz: 200 mil. Um desperdício, porque numa briga fiquei assim. Sei que me da personalidade, mas se tivesse sabido antes, não teria mexido em nada. Continuando. Seios: dois, porque não sou nenhum monstro. 70 mil cada, mas já estão amortizados. Silicone. Lábios, testa, nas maçãs do rosto, quadris e bunda. O litro custa 100 mil. Calculem vocês, porque eu já perdi a conta. Redução de mandíbula, 75 mil. Depilação completa a laser, porque a mulher também veio do macaco, tanto ou mais que o homem, 60 mil por sessão. Depende dos pelos de cada um. Em geral, duas a quatro sessões. Mas se você for uma diva flamenca, vai precisar de mais. Como eu estava dizendo, custa muito caro ser autêntica, senhora. E nessas coisas, não se deve economizar, porque se é mais autêntica quanto mais se parece com o que sonhou para si (Trecho filme Pedro Almodóvar, Tudo sobre minha mãe).

Fica evidente que quando Agrado se pontifica a falar sobre si, resume sua vida às suas mudanças cirúrgicas, deixando claro que sua existência está estritamente ligada à sua fabricação corporal.

No entanto, ao mesmo tempo em que a travesti faz nascer sua identidade através de sua própria fabricação, dá fim à própria imagem de humano dentro de um contexto social, pois ao romper com as fronteiras da inteligibilidade, se põem fora da inteligibilidade social por subverter as fronteiras da própria linguagem.

Volta-se, portanto, a discussão supramencionada acerca da formação do sujeito através do seu reconhecimento sexuado, bem como da continuidade coerente desse reconhecimento no que concerne à identidade de gênero e sexualidade.

Estas atribuições ou interpelações alimentam aquele campo de discurso e poder que orquestra, delimita e sustenta aquilo que pode legitimamente ser descrito como "humano". Nós vemos isto mais claramente nos exemplos daqueles seres abjetos que não parecem apropriadamente generificados; é sua própria humanidade que se torna questionada. $\mathrm{Na}$ verdade, a construção do gênero atua através de meios excludentes, de forma que o humano é não apenas produzido sobre e contra o inumano, mas através de um conjunto de exclusões, de pagamentos radicais, os quais, estritamente falando, recusam a possibilidade de articulação cultural. Portanto, não é suficiente afirmar que os sujeitos humanos são construídos, pois a construção do humano é uma operação diferencial que produz o mais e o menos "humano", o inumano, o humanamente impensável. Esses locais excluídos vêm limitar o "humano" com seu exterior constitutivo, e assombrar aquelas fronteiras com a persistente possibilidade de sua perturbação (BUTLER, 2010, p. 161). 
É possível compreender como as experiências de identidade de gênero da travesti decorrem na sua não consideração como humano, como afirma Sampaio (2009):

A capacidade de viver, portanto, não é fisiológica (mesmo que em casos extremos isso chegue a ser impedido), mas a existência social, o reconhecimento perante ao outro, estabelecendo, desta forma, uma relação entre a noção de inteligibilidade de gênero e humanidade. Ser humano requer morfologias ideais que se adéquam a normas corporais, normas estas que governam a ideia de anatomia humana (SAMPAIO, 2009, p. 63).

É perceptível, deste modo, que ao darem a luz a si mesmas, as travestis contrariam a normatização dos papéis sexuais rígidos, e recebem, como sanção, a sua marginalização e discriminação que resultará na violência social e institucional contra si.

\section{A PLASTICIDADE DOS GÊNEROS}

Quando Judith Butler reconstrói o sujeito hegeliano, Ihe atribui a incumbência de ser um eterno viajante, que nunca se fixa em um destino e nunca permanece o mesmo ao entrar em contato com o mundo exterior. Quando a autora se propõe a definir o gênero, Ihe confere o mesmo estado: é um sujeito em ação; uma sequência de atos (SALIH, 2012).

Salih (2012), ao se referir ao conceito de gênero de Butler, cria uma metáfora para melhor explaná-lo: imagine que exista uma peça pronta para ser encenada; o protagonista sobe ao palco e performatiza seu papel de acordo com o script. Aqui, a sequência de atos que o sujeito, em ação, executa, pode ser entendida como o próprio gênero. Entretanto, o que a autora parece deixar claro, é que por mais que a personagem já tenha sido criada pelo roteiro - e aqui se pode notar a construção discursiva prévia do papel social -, inexiste um ator que espera ansioso nos bastidores, pronto para entrar em cena. Pensar em um ator que antecede a performance é, de certa forma, atribuir uma essência aos indivíduos. 
Ao se referir ao processo de performatividade que o gênero está, o tempo todo, engrenando, Bento (2006) contextualiza o processo de produção do sujeito no âmbito do sistema binário e da matriz heteronormativa. Isso significa dizer que as normas de gênero, através de diversas tecnologias, estão cotidianamente trabalhando para que corpos-machos e corpos-fêmeas sejam constituídos.

Um exemplo muito claro acerca desses dispositivos, que encarceram as verdades dos indivíduos nos corpos, pode ser observado no momento em que o aparelho de ultrassonografia passeia pela barriga da mãe dentro do consultório médico. As palavras mágicas "é um menino" ou "é uma menina", iniciam um processo de inteligibilidade social, ao colocar a futura criança - mesmo antes de nascer - nos confins das normas que prevêem identidades em corpos sexuados. Essa curta frase desencadeará uma série de expectativas sociais que serão responsáveis por uma complexa rede de normalização, que vai desde a escolha do nome, até o uso de roupas, comportamentos, brincadeiras e brinquedos.

Além disso, a infância pode ser apontada como uma fase de extremo controle e conformação, em que as normas de gênero são cotidianamente reiteradas através do que Bento (2008) denomina como heteroterrorismo, ou seja, a proibição de determinados comportamentos - executado pela escola, família, igreja, amigos, etc - que não se inserem em uma lógica de inteligibilidade sexo/gênero. As famosas frases "isso é coisa de menino" ou "isso é coisa de menina", exemplificam de forma clara uma das maneiras pelas quais as crianças são interditadas de performatizarem comportamentos contrários às expectativas das instituições sociais.

No filme "Minha vida em cor de rosa", a personagem Ludovic, apesar de ser um menino, demonstra interesse em coisas que referenciam um mundo eminentemente feminino - vestidos, bonecas, princesas -, e por conta disso, é repreendido em vários momentos, chegando, inclusive, a tentar se moldar às regras que constroem o universo da masculinidade.

Ludovic representa os dramas vividos por várias crianças que não conseguem se adaptar às normas de gênero. Bento (2008) relata que um dos 
motivos dos quais travestis e homens e mulheres transexuais abandonam a escola tão cedo é o fato de não conseguirem suportar as violências cotidianas sofridas nesse ambiente. Isso fica muito claro na fala da mulher transexual Cláudia, entrevistada por Bento (2008):

$\mathrm{Na}$ escola, quando me chamavam de veado ou de macho-fêmea, eu chorava, me afastava de todo mundo, não saía para o recreio. Eu só tenho a $3^{\text {a }}$ série completa. Eu parei em $96 .$. Eu parei de estudar no meio da $4^{\underline{a}}$ série. Notas boas... por causa desse preconceito que eu não aguentava. Não aguentei o preconceito de me chamarem de machofêmea, de veado, de travesti, essas coisas todas (BENTO, 2008, p. 130).

Essas experiências identitárias pelas quais passam as travestis, as mulheres e homens transexuais, as drag queens, os drag kings, os crossdressers, etc, se chocam diretamente com as normas de gênero. Entretanto, por mais que as brechas dos dispositivos heterossexuais tenham dado espaço para a criação de novas performances que ultrapassam o binarismo, o que se observa é que o processo de formação do gênero ininteligível consegue localizar os discursos normalizadores, e desnaturalizar as identidades sexuais.

Quando a travesti encena a feminilidade através dos hormônios, silicones, cabelos, maquiagens, vestidos, demonstra o quão artificial é o processo de fabricação do gênero. A travesti não é uma imitação da mulher; na verdade, ela é a prova de que as próprias técnicas de feminilização utilizadas pelas mulheres são tão artificiais quanto aquelas empregadas pelas travestis.

\section{CONCLUSÃO}

Conforme foi explanado durante o texto, não existe naturalidade na forma como a fêmea humana ou o macho humano desenvolvem suas identidades. Aliás, questionou-se a própria categorização do corpo e do sexo como aparato prédiscursivo.

Foi evidenciado que o sistema binário - criado através de discursos -, divide o mundo em homens e mulheres, cada um dotado de um sexo, simbolizando a completa oposição entre essas duas identidades, que só se 
encontrarão na complementariedade de seus corpos, no contexto da exigência da matriz heterossexual.

O sujeito humano, construído também por tecnologias discursivas, depende da identificação sexuada do indivíduo, que após se reconhecer em um sexo, desenvolverá um gênero em conformidade com os padrões de gêneros inteligíveis. O humano demarcará a fronteira da inteligibilidade social através da negação do inumano, ou abjeto, que estará condenado aos locais inóspitos e inabitáveis da vida social.

Por não expressar seu gênero em conformidade com as regras de gênero, ou seja, desenvolvendo uma performance que leva em consideração a coerência entre sexo/gênero/sexualidade, a travesti está fadada a ocupar o local de abjeção. Contudo, ainda que esteja no lado oposto da fronteira da humanidade, é no seu corpo subversivo que se percebe a plasticidade dos discursos e normas que visam naturalizar as identidades dos indivíduos.

Os processos de mudança corporal pela qual passam as travestis, constituem formas diferenciadas de interpretar através de atos as normas de gênero, evidenciando não só que os corpos não produzem identidade e não encerram as verdades acerca dos indivíduos, como também demonstram que as mulheres passam pelos mesmos processos de feminilização e construção identitária.

\section{REFERÊNCIA}

ALMODÓVAR, Pedro. Tudo sobre minha mãe. Espanha, 1999.

BEAUVOIR, Simone de. O segundo sexo. Rio de Janeiro: Nova Fronteira, 2000.

BENTO, Berenice. A reinvenção do corpo. Sexualidade e gênero na

experiência transexual. Rio de Janeiro: Gramond, 2006

.0 que é transexualidade. São Paulo: Brasiliense, 2008.

BERLINER, Alain. Minha vida em cor de rosa. França, 1997. 
BUTLER, Judith. Corpos que pensam: sobre os limites discursivos do "sexo". In: LOURO, Guacira (org). O corpo educado: pedagogias da sexualidade. Belo Horizonte: Autêntica, 2010.

Problemas de gênero: Feminismo e subversão de identidade. Rio de Janeiro: Civilização Brasileira, 2003.

FOUCAULT, Michel. Microfísica do Poder. Rio de Janeiro: Edição Graal, 2010.

.História da sexualidade 1: A vontade de saber. Rio de Janeiro: Edição Graal, 2009.

GARCIA, Marcos Vieira Roberto. DRAGÕES: Gênero, corpo e violência na formação da identidade entre as travestis de baixa renda. Tese apresentada ao Programa de Pós-Graduação em Psicologia social do Instituto de Psicologia da Universidade de São Paulo: 2007.

HILAIRE, Colette St. A dissolução das fronteiras do sexo. In: SWAIN, Tania Navarro (org). Feminismos: Teorias e Perspectivas. Textos de História: Revista do Programa de Pós-graduação em História da UNB, 2000, vol. 8, n. 1².

KULICK, Don. Travesti, prostituição, sexo, gênero e cultura no Brasil. Rio de Janeiro: Editora Fiocruz, 2008.

LOURO, Guacira Lopes. Pedagogias da sexualidade. In: LOURO, Guacira (org). 0 corpo educado: pedagogias da sexualidade. Belo Horizonte: Autêntica, 2010.

NOVO DICIONÁRIO AURÉLIO. Rio de Janeiro: Editora Nova Fronteira, 2004.

SALIH, Sara. Judith Butler e a teoria queer. Belo Horizonte: Editora Autêntica, 2012.

SAMPAIO, Juciana Oliveira de. Incorporações e compartilhamento do desejo: Notas sobre a corporalidade e o caráter associativo entre travestis de São Luís. Dissertação apresentada ao Programa de Pós-Graduação em Ciências Sociais da Universidade Federal do Maranhão, 2009.

SILVA. Hélio R. S. Travestis, entre o espelho e a rua. Rio de Janeiro: Rocco, 2007.

ZAMBRANO, Margarida Camacho. Las políticas Del cuerpo y lãs negociaciones indetitarias de lãs travestis em el ex. Penal García Moreno. Tese de mestrado apresentada à Universidade Andina Simòn Bolívar: 2006. 